\title{
Preparation of Graft Copolymer by Radical Copolymerization of Vinylbenzyl-Type Polyamide Macromonomer with 2-Vinylpyridine and Facilitated Permeation of Cupric Chloride through Its Crosslinked Membrane
}

\author{
Kazuhiko Hashimoto, Housei ShINOdA, Masahiko OKada, \\ and Hiroshi Sumitomo \\ Faculty of Agriculture, Nagoya University, Furo-cho, Chikusa-ku, \\ Nagoya 464-01, Japan
}

(Received October 9, 1989)

\begin{abstract}
A polyamide macromonomer (1) having a vinylbenzyl group at one chain end was copolymerized with 2-vinylpyridine (VP) using a radical catalyst in $N, N$-dimethylformamide at $60^{\circ} \mathrm{C}$. The resulting graft copolymer composed of a poly(VP) stock and polyamide branches was separated from the unreacted $\mathbf{1}$ by fractional precipitation in dimethyl sulfoxide-water mixed solvent. A graft copolymer membrane was easily prepared by casting a methanol solution of the copolymer, while a homopolymer of VP had poor film-forming ability. The crosslinked membrane was found to exhibit extremely high permeability of cupric chloride in aqueous solution.

KEY WORDS Bicyclic Lactam / Polyamide / Macromonomer / Graft Copolymer / Membrane / Permeation / Cupric Chloride / 2-Vinylpyridine /
\end{abstract}

As described in preceding papers, ${ }^{1,2}$ a vinylbenzyl-type macromonomer having a polyamide chain (1) was prepared by anionic polymerization of bicyclic oxalactam, 8-oxa-6azabicyclo[3.2.1]octan-7-one (abbreviated as BOL, 2). This was the first macromonomer prepared from lactam. The radical copolymerization of 1 with styrene gave a graft copolymer composed of polystyrene as a stock and hydrophilic polyamide as branches. ${ }^{1,2}$ The resulting copolymer was effective for surface modification of hydrophobic polystyrene film. ${ }^{1,2}$ Therefore $\mathbf{1}$ is expected to be copolymerized with other comonomers to give various graft copolymers useful for polymeric composite materials.

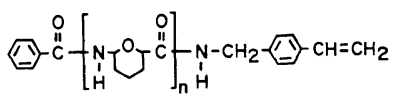

1

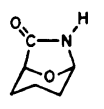

2
Vinylpyridines are known to be useful comonomers, because of their ability to form complexes at the basic nitrogen atoms. $^{3}$ Therefore, composites of $\mathbf{1}$ and poly(vinylpyridine)s are also expected to be attractive. In the present study, 1 was copolymerized with 2-vinylpyridine (VP) by a radical catalyst. The resulting graft copolymer was cast to make a hydrophilic membrane and the permeability of some metal ions through the crosslinked copolymer membrane was determined in aqueous solution.

\section{EXPERIMENTAL}

\section{Radical copolymerization of $\mathbf{1}$ with VP}

$\mathrm{Vp}$ was distilled under reduced pressure. The preparation of $\mathbf{1}$ and purification of the other reagents were carried out by the same procedures reported earlier. ${ }^{1,2,4,5}$ VP $(0.99 \mathrm{~g}), \mathbf{1}$, $\left(M_{n}, 4100 ; 0.50 \mathrm{~g}\right)$ and azobisisobutyronitrile 
(AIBN, $3.2 \mathrm{mg}$ ) were dissolved in $1.5 \mathrm{~g}$ of DMF in an ampoule. After being degassed three times in a cooling bath, the ampoule was sealed and kept at $60^{\circ} \mathrm{C}$ for $24 \mathrm{~h}$. The polymerization mixture was poured into a large amount of $n$-hexane-acetone mixed solvent $(3: 1, \mathrm{v} / \mathrm{v})$. The precipitate containing the graft copolymer and the unreacted $\mathbf{1}$ was collected, washed with the mixed solvent, and dried in vacuo.

The whole polymer was dissolved in dimethyl sulfoxide $\left(\mathrm{Me}_{2} \mathrm{SO}\right)$ to obtain a $2 \%$ solution, to which a $\mathrm{Me}_{2} \mathrm{SO}$-water mixture $(4: 1, \mathrm{v} / \mathrm{v})$ was added drop by drop with vigorous stirring at room temperature. When the volume ratio of $\mathrm{Me}_{2} \mathrm{SO}$ to water in the system reached $6: 1$, the precipitated graft copolymer was separated by centrifugation from the solution, and then purified by reprecipitation using chloroform and diethyl ether. The unreacted $\mathbf{1}$ was also recovered from the residual solution after centrifugation.

The radical homopolymerization of VP was carried out by the same procedure. The polymerization mixture was poured into large amount of water. The precipitated polymer was purified by repeated immersion in water, followed by freeze-drying from a benzene solution.

\section{Preparation of a Crosslinked Membrane from Graft Copolymer}

The isolated graft copolymer, $\left(M_{n}, 54000\right.$; weight fraction of polyamide sequence, 0.17 ; number of polyamide branches, $2.0 ; 0.35 \mathrm{~g}$ ) and 1,6-dibromohexane $(0.027 \mathrm{~g}, 4 \mathrm{~mol} \%$ to VP units in copolymer) were dissolved in $12 \mathrm{ml}$ of methanol. The solution was spread on a glass plate and dried at room tempetature for several days. The plate was then heated at $65^{\circ} \mathrm{C}$ for more than $30 \mathrm{~h}$ for crosslinking and then immersed in water-acetone mixture $(20: 1, \mathrm{v} / \mathrm{v})$ for peeling to give a semitransparent membrane, of which the thickness was about $50 \mu \mathrm{m}$. After immersed in both $0.05 \mathrm{~N}$ hydrochloric acid and ammonia aqueous solution for several hours, the membrane was washed by repeated immersion in deionized water.

A membrane was immersed into an 0.05 moll $1^{-1}$ aqueous solution of metal chloride at $25^{\circ} \mathrm{C}$ for 3 days. After the solution attached to the membrane was removed by dipping it into deionized water for a few seconds, the chloride dissolved in the membrane was repeatedly extracted with deionized water. The chloride content in the membrane was determined by conductometry of the combined water extracts. The solubility coefficient $(S)$ was estimated by eq 1:

$$
S=c_{\mathrm{m}} / c_{\mathrm{s}}
$$

where $c_{\mathrm{s}}$ and $c_{\mathrm{m}}$ represent the concentrations of chloride in the aqueous solution and in the membrane, respectively.

\section{Permeation of Metal Chlorides through Cross-} linked Copolymer Membrane

The permeation rate of metal chlorides was measured using a cylindircal cell, spearated into two compartments by a membrane. The effective area of the membrane was $3.8 \mathrm{~cm}^{2}$. One of the chambers was filled with $48 \mathrm{ml}$ of an $0.05 \mathrm{moll}^{-1}$ aqueous solution of metal chloride (side 1), and the other with $48 \mathrm{ml}$ of deionized water (side 2). The cell was maintained at $25.0 \pm 0.1^{\circ} \mathrm{C}$ in a thermostated bath. The concentration of the chloride transported into the receiving phase was monitored by conductometry at specified intervals.

Assuming Fick's first law, the permeability coefficient $(P)$ was evaluated to eq $2^{6,7}$ :

$$
\begin{aligned}
-\ln [1- & \left.\left(\left(V_{2} / V_{1}\right)+1\right) c_{2} / c_{0}\right] \\
= & {\left[\left(V_{2} / V_{1}\right)+1\right] \cdot\left(A / V_{2} \cdot \Delta x\right) \cdot P \cdot t }
\end{aligned}
$$

where $c_{0}$ is the initial concentration of chloride in the side 1's solution; $c_{2}$, the concentration of chloride in the side 2's solution after the permeation test for $t$ seconds; $A$, the effective area of membrane; $\Delta x$, the thickness of membrane; $V_{1}$ and $V_{2}$, volumes of solutions in the sides of chambers. The value of $P$ was calculated from the slope of the linear part of the curve obtained by plotting the left term in 
eq 2 against $t$.

\section{Characterization}

${ }^{1} \mathrm{H}$ NMR spectrum of graft copolymer was measured on a JEOL JNM-FX-200 Fourier transform high resolution spectrometer operating at $200 \mathrm{MHz}$ in dimethyl sulfoxide- $d_{6}$ at $50^{\circ} \mathrm{C}$. Gel permeation chromatograms were recorded on a Hitachi Model 634A high performance liquid-chromatograph apparatus (column, Shodex GPCA 803 $\rightarrow 804,8 \phi \times 1000$ $\mathrm{mm}$; solvent chloroform). The DSC thermogram of copolymer was taken with a PerkinElmer Model DSC-2 differential scanning calorimeter. Conductance of the aqueous solution was measured with a Toa Electronics Model CM-5B conductometer using a CG$7001 \mathrm{PL}$ cell at $25^{\circ} \mathrm{C}$.

\section{RESULTS AND DISCUSSION}

\section{Polyamide Macromonomer}

As described in previous articles, ${ }^{1,2}$ the vinylbenzyl-type polyamide macromonomer (1) whose number average molecular weight was about $4,100-4,300$, was prepared by the anionic polymerization of $\mathbf{2}$ activated with $5 \mathrm{~mol} \%$ of $\mathrm{N}$-benzoyl derivative of 2 and the following reaction of the reactive chain end with $p$-vinylbenzylamine in $\mathrm{Me}_{2} \mathrm{SO}$ at $25^{\circ} \mathrm{C}$. The terminal group proved to be quantitatively functionalized with the amine by NMR and UV spectroscopies. ${ }^{1,2}$

Many macromonomers have been prepared by living or quasiliving polymerization combined with an introduction of a polymerizable functional group either on the initiation or on the termination step..$^{8-10}$ The key point for the preparation of polyamide macromonomers is expected to be in suppressing of possible side reactions in the anionic polymerization of lactams, which should be caused mainly by the proton-withdrawing reaction on the $\alpha$-carbon atom of the lactam-carbonyl groups. ${ }^{11}$ The $\mathrm{p} K_{\mathrm{a}}$ value of the methine proton adjacent to the lactam-carbonyl group in $\mathbf{2}$ should be relatively high, because it is located at the bridge-head of the rigid bicyclic molecular structure. In addition, the kinetic polymerizability is so high that the quasiliving polymerization of $\mathbf{2}$ proceeds under mild conditions described above, and the resulting polyamide (3) having an acyllactam-type reactive end group can be isolated from the polymerization system. ${ }^{12-14}$ Therefore, the end capping of the reactive group with $p$-vinylbenzylamine is inferred to have proceeded quantitatively to give the polyamide macoromonomer functionalized by vinylbenzyl group. ${ }^{1,2}$

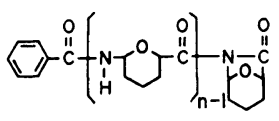

3

\section{Radical Copolymerization}

The results of the radical copolymerization of $1\left(M_{1}\right)$ with VP $\left(M_{2}\right)$ are summarized in Table I. The copolymerization in each feed composition proceeded homogeneously in $\mathrm{DMF}$ at $60^{\circ} \mathrm{C}$. The gross polymer insoluble in $n$-hexane-acetone $(3: 1, \mathrm{v} / \mathrm{v})$ mixed solvent was quantitatively recovered as colorless powder, which was expected to contain the resullting graft copolymer and unreacted $\mathbf{1}$ as shown in gel permeation chromatographs (Figure 1). Since 1 is insoluble in the mixed solvent, the unreacted 1 should be contained quantitatively in the recovered gross polymer. Therefore, the conversion of VP was calculated from the weight of the recovered whole polymer and its composition estimated by ${ }^{1} \mathrm{H}$ NMR spectroscopy.

In order to separate the resulting graft copolymer from the unreacted $\mathbf{1}$, the polymer mixture was provided for the fractional precipitation using dimethyl sulfoxide and water as a diluent and a precipitant, as described in the experimental section. The GPC charts in Fig. 1 show that the present method is effective for our purpose. The unreacted 1 recovered after separation of the graft 
Table I. Radical copolymerization of polyamide macromonomer $\left(\mathrm{M}_{1}\right)$ with 2-vinylpyridine $\left(\mathrm{M}_{2}\right)^{\mathrm{a}}$

\begin{tabular}{|c|c|c|c|c|c|c|c|c|c|c|c|c|}
\hline \multirow{2}{*}{$\begin{array}{l}\text { Run } \\
\text { No. }\end{array}$} & \multicolumn{2}{|c|}{$\mathrm{M}_{1}$} & \multirow{2}{*}{$\frac{\mathrm{M}_{2}}{\mathrm{~g}}$} & \multirow{2}{*}{$\frac{\begin{array}{c}\text { Recovered } \\
\text { polymer }^{\text {b }}\end{array}}{\mathrm{g}}$} & \multirow{2}{*}{$\frac{\begin{array}{c}\text { Copolymer } \\
\text { yield }^{\mathrm{c}}\end{array}}{\mathrm{g}}$} & \multirow{2}{*}{$\begin{array}{c}\begin{array}{c}\mathrm{M}_{1} \text { in } \\
\text { copolymer }\end{array} \\
\mathrm{mol} \%\end{array}$} & \multicolumn{2}{|c|}{$\begin{array}{c}\text { Conversion } \\
\%\end{array}$} & \multirow{2}{*}{$\frac{1}{r_{2}}$} & \multirow{2}{*}{$\begin{array}{c}M_{w}^{d} \\
\times 10^{-4}\end{array}$} & \multirow{2}{*}{$\begin{array}{l}M_{n}^{\mathrm{d}} \\
\times 10^{-4}\end{array}$} & \multirow{2}{*}{$\begin{array}{c}\text { Number } \\
\text { of } \\
\text { branches }\end{array}$} \\
\hline & $M_{n}$ & $\begin{array}{l}\mathrm{mol} \% \\
\text { in feed }\end{array}$ & & & & & $\mathrm{M}_{1}$ & $\mathrm{M}_{2}$ & & & & \\
\hline 1 & 4300 & 2.3 & 0.52 & 0.79 & 0.51 & $1.4^{\mathrm{h}}$ & 42 & 67 & 0.49 & 9.9 & 5.2 & 4.6 \\
\hline 2 & 4100 & 1.3 & 0.99 & 1.33 & 1.08 & 0.81 & 54 & 86 & 0.40 & 13.9 & 7.1 & 4.1 \\
\hline 3 & 4300 & 0.81 & 1.49 & 1.57 & 1.14 & 0.45 & 42 & 75 & 0.39 & 12.5 & 5.4 & 2.0 \\
\hline 4 & - & 0 & $1.93^{\mathrm{f}}$ & $1.29^{\mathrm{g}}$ & - & - & - & 67 & - & $11.1(12.7)^{\mathrm{i}}$ & 5.3 & 0 \\
\hline
\end{tabular}

${ }^{\text {a }} \mathrm{M}_{1}, 0.50 \mathrm{~g}$; AIBN, $0.2 \mathrm{~mol} \%$ to monomer; DMF, $1.5 \mathrm{~g}$; temp., $60^{\circ} \mathrm{C}$; time, $24 \mathrm{~h}$.

b Insoluble in $n$-hexane-acetone $(3: 1, \mathrm{v} / \mathrm{v})$ mixture.

c Insoluble in $\mathrm{Me}_{2} \mathrm{SO}$-water $(6: 1, \mathrm{v} / \mathrm{v})$ mixture.

d Determined by GPC (polystyrene standard).

e Calculated from the composition and molecular weight of the copolymer.

f Homopolymerization (solvent, DMF, $3.0 \mathrm{~g}$ ).

g Insoluble in water.

${ }^{\text {h }}$ Elemental analysis: calcd from the copolymer composition determined by ${ }^{1} \mathrm{H}$ NMR; C, 71.70\%; $\mathrm{H}, 6.90 \%$; N, $12.30 \%$ : Found; C, $71.68 \% ; \mathrm{H}, 6.96 \% ; \mathrm{N}, 12.51 \%$.

$\mathrm{i}$ The value in parenthesis was determined by viscometry in methanol at $25^{\circ} \mathrm{C} .{ }^{18}$

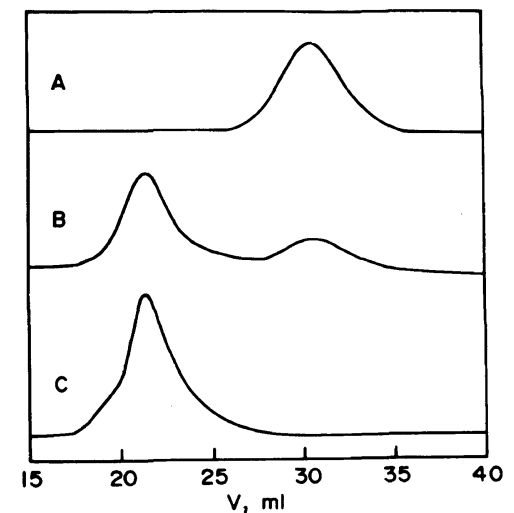

Figure 1. GPC curves of polymers (column, Shodex GPCA $803 \rightarrow 804,8 \phi \times 1000 \mathrm{~mm}$; chloroform). A, Polyamide macromonomer $\left(M_{n}, 4,300\right)$; B, whole polymer recovered after radical copolymerization of polyamide macromonomer and 2-vinylpyridine; C, graft copolymer isolated by fractional precipitation.

copolymer was also found to be the same as the original one by ${ }^{1} \mathrm{H}$ NMR and GPC analyses.

The isolated polymer proved to have both polyamide and poly(VP) sequences by ${ }^{1} \mathrm{H}$ NMR spectroscopy as shown in Figure 2. The mole fraction of macromonomer unit in the

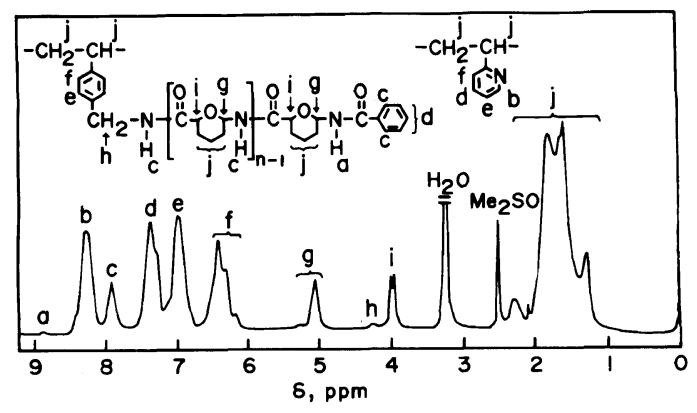

Figure 2. ${ }^{1} \mathrm{H}$ NMR spectrum of graft copolymer obtained by radical copolymerization of polyamide macromonomer $\left(M_{n}, 4,100\right)$ with 2-vinylpyridine $\left(M_{n}, 71,000\right.$; weight fraction of BOL unit in copolymer, $0.22 ; \mathrm{Me}_{2} \mathrm{SO}$ $d_{6}$; TMS; $50^{\circ} \mathrm{C} ; 200 \mathrm{MHz}$ ).

copolymer $(y)$ can be determined from peak intensities in the spectrum by using the following equation (eq 3 ) and listed in Table I.

$$
y=G / n B
$$

where $B$ and $G$ are the relative intensities of peaks $b$ and $g$ in Figure 2, respectively. The symbol $n$ represents the degree of polymerization of 1 . The results of the elemental analysis of the copolymer were consistent with those 
calculated from the copolymer composition estimated by ${ }^{1} \mathrm{H}$ NMR spectroscopy, as shown in the footnote $\mathrm{h}$ in Table $\mathrm{I}$. Therefore, the estimated values of $y$ are reliable. They are always smaller than those in the corresponding feeds, which suggests that the apparent polymerizability of $\mathbf{1}$ is lower than that of VP in the present copolymerization.

The conversion of $\mathbf{1}$ was also calculated from the yield of the graft copolymer and its composition. From the conversions of $\mathrm{M}_{1}$ and $\mathrm{M}_{2}$ the monomer reactivity ratio $\left(r_{2}\right)$ was calculated ${ }^{15}$ and the relative reactivity of 1 with VP radical was estimated by the values of $1 / r_{2}$ (Table I). The values are evidently lower than that of styrene $\left(1 / r_{2}=0.88\right) .{ }^{16,17}$ Since the $1 / r_{2}$ value for the reaction of 1 with styryl radical $(0.5-0.6)$ was also lower than that for the reaction of styrene itself, ${ }^{2}$ one of the reasons for the lower polymerizability of $\mathbf{1}$ may be the low compatibility between 1 and comonomers, as discussed by several investigators. ${ }^{10,19,20}$

\section{Characterization of Graft Copolymer}

The number average molecular weight of the copolymer was estimated to be above 50,000 by gel permeation chromatography using polystyrene as the standard. Therefore the present copolymer is speculated to have several polyamide branches, whose molecular weights are about 4,000.

The copolymer is soluble not only in $\mathrm{Me}_{2} \mathrm{SO}$, DMF, chloroform, and pyridine, but also in methanol, ethanol, and dilute hydrochloric acid aqueous solution, in which $\mathbf{1}$ is insoluble or only swollen, at room temperature. In addition the copolymer seems to have an ability to solubilize 1 in methanol. In other words, 1 was soluble in methanol in the presence of the graft copolymer at room temperature, although insoluble in the absence of the copolymer.

The fusion of the graft copolymer was observed at $245-265^{\circ} \mathrm{C}$ by differential scanning calorimetry, while the homopolymer of VP was amorphous at room temperature.
From this fact, the copolymer is elucidated to contain the polyamide domains, which have strong intermolecular interactions effective for film-forming ability. ${ }^{2,4,5,21}$ Therefore, the graft copolymer membrane is speculated to have been easily prepared from a methanol solution of the copolymer, althoguh a homopolymer of VP has poor film-forming ability.

\section{Permeation through Crosslinked Copolymer Membrane}

The copolymer membrane crosslinked by 1,6-dibromohexane is swollen but insoluble even in dilute hydrochloric acid aqueous solution. By taking account of the literature on the quarternization of pyridine rings with alkyl halides, ${ }^{2-24}$ the structure of the crosslinked point is speculated to be 4 . Although the amount of $\mathbf{4}$ forming crosslinked points has not been estimated, it is presumed not to be much from the weight of 1,6-dibromohexane added into the copolymer solution on casting.

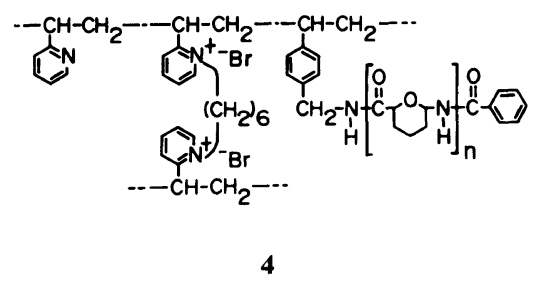

The degree of hydration of the present membrane was 0.32 in deionized water. Such high hydrophilicity is caused not only by quaternary pyridine rings but also by polyamide branches. Therefore, the membrane can be presumed to exhibit significantly high permeability of polar molecules such as water, metal ions, and so on.

The permeation of various metal chlorides through the membrane was examined as shown in Figure 3. Cupric chloride was found to permeate much faster than the others through the membrane. During the permeation, the membrane was swollen possibly as a result of electrostatic repulsion among pyridine rings charged by coordination to cupric ions as 


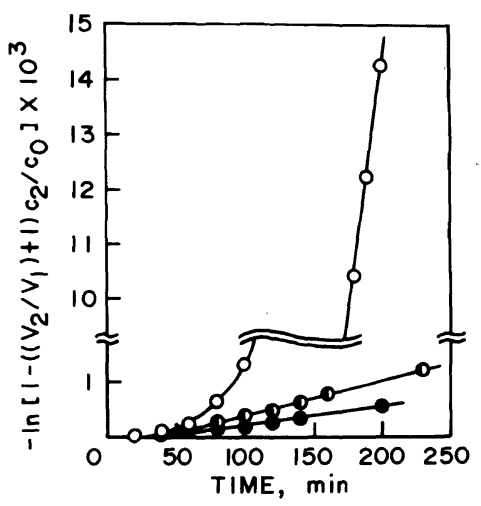

Figure 3. Permeability of various metal chlorides in aqueous solution at $25^{\circ} \mathrm{C}$ through crosslinked membrane prepared from graft copolymer having a poly(2-vinylpyridine) stock and polyamide branches (run No. 3 in Table I). Feed, $0.05 \mathrm{moll}^{-1}, 48 \mathrm{ml}: \mathrm{O}, \mathrm{CuCl}_{2} ; \boldsymbol{O}, \mathrm{CdCl}_{2}$; - $\mathrm{NiCl}_{2}$.

Table II. Permeation of various metal chlorides through the crosslinked graft copolymer membrane ${ }^{a}$

\begin{tabular}{|c|c|c|c|c|}
\hline \multirow{2}{*}{$\begin{array}{c}\text { Metal } \\
\text { chloride }\end{array}$} & \multirow{2}{*}{$\begin{array}{l}\text { Degree of } \\
\text { swelling }\end{array}$} & \multirow{2}{*}{$\frac{P \times 10^{8}}{\mathrm{~cm}^{2} \mathrm{~s}^{-1}}$} & \multirow{2}{*}{$S$} & \multirow{2}{*}{$\frac{D \times 10^{9}}{\mathrm{~cm}^{2} \mathrm{~s}^{-1}}$} \\
\hline & & & & \\
\hline $\mathrm{CuCl}_{2}$ & 1.4 & 10 & 7.1 & 15 \\
\hline $\mathrm{CdCl}_{2}$ & 1.0 & 0.46 & 3.2 & 1.4 \\
\hline $\mathrm{NiCl}_{2}$ & 1.0 & 0.24 & 0.83 & 2.9 \\
\hline $\mathrm{NaCl}$ & 1.0 & 0.34 & 0.44 & 7.8 \\
\hline
\end{tabular}

a aqueous solution at $25^{\circ} \mathrm{C}$.

b Ratio of diameter of membrane in chloride solution to that in deionized water.

described later. By taking account of the swelling of the membranne, the permeability coefficients $(P)$ were calculated using eq 2 and are summarized in Table II. The value of $P$ for cupric chloride was larger than that for sodium chloride by about 30 times.

Since such high permeability of cupric chloride was not observed in the homopolyamide membrane, the interaction of the chloride with polyamide branches in the graft copolymer membrane may be not so important to the permeation of the chloride. On the other hand, poly(4-vinylpyridine) and poly(VP) are known to have strong coordination ability to various metal ions. ${ }^{22-25}$ Therefore, the present membrane containing poly(VP) domains is also expected to show similar coordination ability. The solubility coefficients $(S)$ of chlorides in the membrane were also determined and summarized in Table II. Again, the value for cupric chloride was found to be the highest among them. The observed order of $S$ for various chlorides was similar to that on Nishide et al.'s data for the amounts of metal ions adsorbed in the crosslinked poly(4-vinylpyridine) resin, which decreased in the following order: $\mathrm{Cu}^{2+}(88 \%)>\mathrm{Ni}^{2+}(55 \%)>\mathrm{Cd}^{2+}$ $(5 \%) .{ }^{22}$ Even sodium chloride, which has no specific interaction with pyridine rings, showed considerably high solubility in the membrane. This may be caused by the high degree of hydration of the membrane.

Such coordination of pyridine rings to metal ions is speculated to decrease their diffusion. At least, however, the mobility of metal ions in the membrane containing poly(VP) domains should be higher than that in poly(4-vinylpyridine), because the former interaction with the pyridine rings should be weaker than the latter one due to the greater steric hindrance around the nitrogen atoms in poly(VP) chains. Diffusion constant $(D)$ can be generally estimated by division of the permeability coefficient $(p)$ with the solubility coefficient $(S){ }^{6}$ Therefore, the values of $D$ for chlorides were determined and are summarized in Table II. The values for cadmium and nickel chlorides were lower than that for sodium chloride, as expected. On the other hand the diffusion of cupric chloride in the membrane was faster than that of sodium chloride. The swelling of the membrane in the solution may suppress the decrease of the mobility of cupric chloride by coordination of pyridine rings.

In summary, the graft copolymer obtained by radical copolymerization of polyamide macromonomer and 2-vinylpyridine was found to be easily cast to the membrane, which had high permeability of cupric chloride in aqueous solution. The facilitated permeation is thought 
to be mainly due to high solubility of cupric chloride in the membrane.

\section{REFERENCES}

1. K. Hashimoto, H. Sumitomo, and M. Kawasumi, Polym. Bull., 11, 121 (1984).

2. K. Hashimoto, H. Sumitomo, and M. Kawasumi, Polym. J., 17, 1045 (1985).

3. H. F. Mark, N. G. Gaylord, and N. M. Bikales, Eds., "Encyclopedia of Polymer Science and Technology," Vol. 14, Wiley, New York, 1971, p 637.

4. H. Sumitomo and K. Hashimoto, Macromolecules, 10, 1327 (1977).

5. K. Hashimoto and H. Sumitomo, Macromolecules, 13, 786 (1980).

6. "Diffusion in Polymers," J. Crank and G. S. Park, Eds., Academic Press, London and New York, 1968, p 232.

7. I. Satake, H. Nakajima, and H. Noguchi, Maku (Japan), 2, 225 (1977).

8. R. Milkovich, "Anionic Polymerization. Kinetics, Mechanism and Synthesis," J. E. McGrath, Ed., ACS Symp. Ser., 166, 41 (1981) and references therein.

9. P. F. Rempp and E. Franta, Adv. Polym. Sci., 58, 1 (1984).

10. Y. Chujo and Y. Yamashita, "Telechelic Polymers: Synthesis and Applications," E. J. Goethals, Ed.,
CRC Press, Boca Ration, Florida, 1989, p 163.

11. J. Sebenda and J. Hauer, Polym. Bull., 5, 529 (1981).

12. K. Hashimoto, H. Sumitomo, and H. Shinoda, Polym. J., 20, 321 (1988).

13. K. Hashimoto, H. Sumitomo, and A. Washio, $J$. Polym. Sci., Polym. Chem. Ed., 27, 1915 (1989).

14. K. Hashimoto, H. Sumitomo, H. Shinoda, and A. Washio, J. Polym. Sci., Polym. Lett. Ed., 27, 307 (1989).

15. J. Kennedy and C. Y. Lo, Polym. Bull., 8, 63 (1982).

16. C. Walling, E. R. Briggs, and K. B. Wolfstirn, J. Am. Chem. Soc., 70, 1543 (1948).

17. C. G. Overberger and F. W. Michelotti, J. Am. Chem. Soc., 80, 988 (1958).

18. S. Arichi, Bull. Chem. Soc. Jpn., 39, 439 (1966).

19. K. Ito, Y. Masuda, T. Shintani, T. Kitano, and Y. Yamashita, Polym. J., 15, 443 (1983).

20. R. Asami and M. Takaki, Makromol. Chem. Suppl., 12, 163 (1985).

21. K. Hashimoto, H. Sumitomo, and H. Yamamori, Polym. J., 19, 1139 (1987).

22. H. Nishide and E. Tsuchida, Makromol. Chem., 177, 2295 (1976)

23. H. Nishide, J. Deguchi, and E. Tsuchida, Bull. Chem. Soc. Jpn., 49, 3498 (1976).

24. H. Biedermann, E. Griessl, and K. Wichmann, Makromol. Chem., 172, 49 (1973).

25. S. Tazuke and S. Okamura, J. Polym. Sci. A-1, 5, 1083 (1967). 